\title{
Modulation of Inspiratory Drive to Phrenic Motoneurons by Presynaptic Adenosine $A_{1}$ Receptors
}

\author{
Xiao-Wei Dong and Jack L. Feldman \\ Systems Neurobiology Laboratory, Department of Physiological Science, University of California Los Angeles, Los \\ Angeles, California 90095-1527
}

The involvement and mechanisms of adenosine $A_{1}$ receptors in regulating bulbospinal synaptic transmission of inspiratory drive to phrenic motoneurons were investigated. The adenosine analog $\mathrm{N}^{6}$-cyclopentyladenosine (CPA) induced a dose-dependent decrease of both inspiratory-modulated activity of $\mathrm{C}_{4}$ ventral roots and synaptic currents of phrenic motoneurons in an in vitro brainstem/spinal cord preparation from neonatal rats. No significant changes were observed in steady-state membrane current (during the expiratory phase). The depressant action of CPA on inspiratory drive was blocked by the selective $A_{\text {, receptor }}$ antagonist 8-cyclopentyltheophylline (CPT). The adenosine receptor antagonist 3-isobutyl-1-methylxanthine (IBMX) induced varying degrees of enhancement of inspiratory-modulated synaptic current, as did CPT. This suggests a role of endogenous adenosine in synaptic transmission of respiratory drive to phrenic motoneurons. The relative contribution of pre- and postsynaptic adenosine receptors was examined by looking at the effects of CPA on postsynaptic membrane properties and on spontaneous or miniature excitatory postsynaptic currents (EPSCs). CPA had no detectable effect on the input resistance of phrenic motoneurons. Moreover, the inward currents of phrenic motoneurons in response to exogenously applied glutamate were not affected by adenosine-related compounds. On the other hand, CPA produced a significant decrease in the frequency of spontaneous and of miniature EPSCs. We conclude that adenosine can modulate transmission of inspiratory drive from bulbospinal neurons to phrenic motoneurons via presynaptic $A_{1}$ receptors.

[Key words: adenosine, $A_{1}$ receptor, synaptic transmission, presynaptic, phrenic motoneurons, respiration]

Precise modulation of transmission of inspiratory drive to phrenic motoneurons that innervate the diaphragm is critical to control respiratory movements necessary for blood gas regulation. We have proposed that the transmission of excitatory inspiratory drive from bulbospinal neurons to phrenic motoneurons (Ellenberger and Feldman, 1988) is mediated by an excitatory amino acid (EAA) transmitter (McCrimmon et al., 1989; Liu et al.,

Received Aug. 30, 1994; revised Nov. 7, 1994; accepted Nov. 10, 1994

This work was supported by NIH Grant NS24742. We thank Drs. S. M Johnson and G. D. Funk for comments in the preparation of the manuscript.

Correspondence should be addressed to Xiao-Wei Dong, Ph.D., Systems Neurobiology Laboratory, Department of Physiological Science, University of California at Ios Angeles, 2927 Iife Science Building, Ios Angeles, CA 90095-1527.

Copyright $\subseteq 1995$ Society for Neuroscience $0270-6474 / 95 / 153458-10 \$ 05.00 / 0$
1990) acting principally at postsynaptic non-NMDA receptors (Liu et al., 1990; Feldman and Smith, 1994). Many putative neuromodulators are present in the phrenic nucleus (Zhan et al., 1989; Ellenberger et al., 1992), suggesting that the modulation of respiratory inputs involves multiple mechanisms (Feldman et al., 1990; Feldman and Smith, 1994).

In this study we examined the actions of adenosine, an important modulator of synaptic function (Phillis and Wu, 1981; Dunwiddie, 1985; Nicoll et al., 1990; Greene and Haas, 1991). Adenosine acts on two distinct types of receptors, $A_{1}$ and $A_{2}$, which inhibit or stimulate adenylate cyclase, respectively (van Calker et al., 1979; Londos el al., 1980; Stiles, 1992). Via $A_{1}$ receptors (Dunwiddie and Fredholm, 1989; Alzheimer et al., 1991; Lambert and Teyler, 1991), adenosine has marked inhibitory effects on excitatory synaptic transmission (Dunwiddie and Hoffer, 1980; Okada and Ozawa, 1980; Prince and Stevens, 1992). The underlying mechanism may involve presynaptic and/ or postsynaptic actions. Adenosine significantly decreases the probability of neurotransmitter release without affecting the size of miniature excitatory postsynaptic currents (EPSCs) in hippocampal slices (Prince and Stevens, 1992; Scanziani et al., 1992; Scholz and Miller, 1992), suggesting an exclusive presynaptic action. Other studies, however, suggest that adenosine-induced inhibition also involves postsynaptic mechanisms (Proctor and Dunwiddie, 1987; Thompson et al., 1992).

The involvement of adenosine in regulating respiration is suggested by the depressant effect of centrally applied adenosine analogs on respiratory rate and depth (Lagercrantz et al., 1984; Barraco et al., 1990; Bissonnette et al., 1991). Little is known, however, about the precise brain site(s) and the mechanism of the action. It has been reported that adenosine reduces spinal motoneuron excitability (Mynlieff and Beam, 1994). Thus, adenosine-induced decrease in inspiratory depth may involve the depression of the inspiratory drive of spinal respiratory motoneurons (e.g., phrenic motoneurons). We thus explored the role of adenosine receptors in regulating activity of phrenic motoneurons by obtaining whole-cell patch-clamp recordings in an isolated brainstem/spinal cord preparation from neonatal rat. This preparation generates a respiratory rhythm, which is transmitted to spinal respiratory motoneurons (Feldman and Smith, 1989; Liu et al., 1990), allowing us to study modulation of excitatory synaptic transmission of motor drive in an identified endogenously driven synapse. We determined whether inspiratory drive to phrenic motoneurons is affected by activation of adenosine $A_{1}$ receptors by examining the effects of exogenous application of adenosine receptor-related drugs on synaptic currents and postsynaptic membrane properties. We then investigated the 


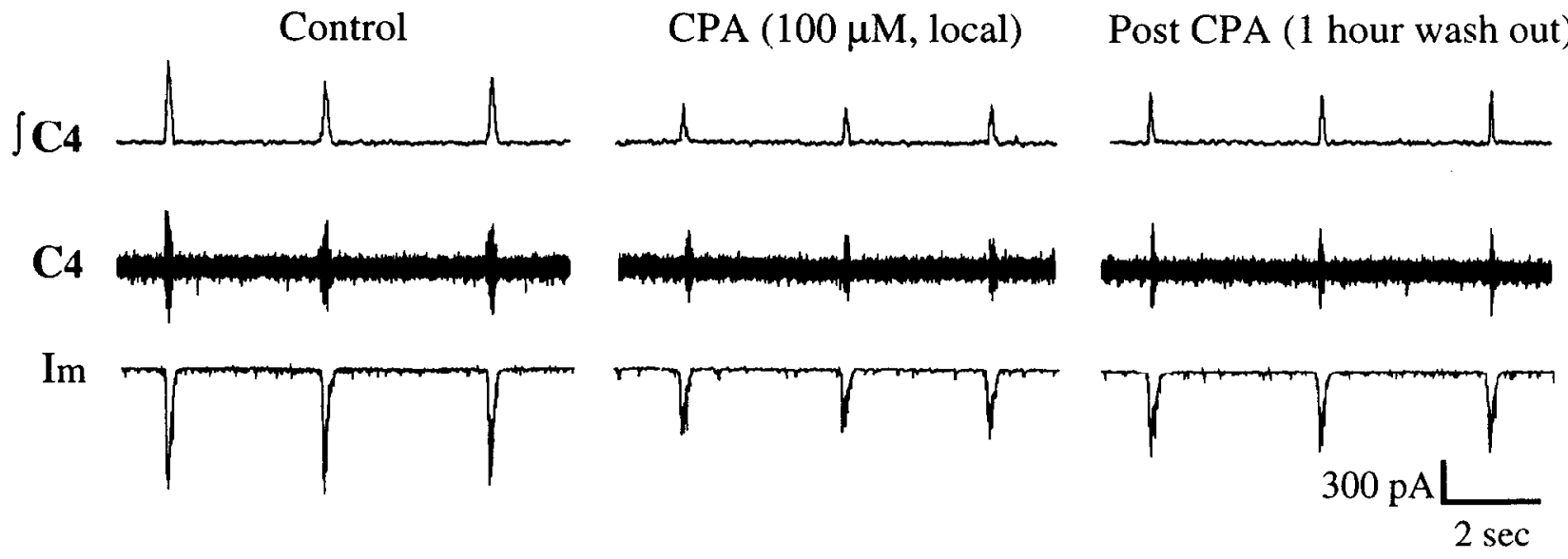

Figure 1. Activation of adenosine receptors depresses bulbospinal inspiratory drive transmission. Local application of CPA simultaneously decreased activity of the $\mathrm{C}_{1}$ ventral root $\left(\int C 4, C 4\right)$ and inspiratory-modulated synaptic current of a phrenic motoneuron $(\mathrm{Im})$ that was voltage-clamped at the end-expiratory potential of $-70 \mathrm{mV}$. Left, control; middle, steady-state activity recorded after 1 min local application of CPA over phrenic motoneuron pool; right, 60 min after the termination of CPA application. Note that at this time both $\mathrm{C}_{4}$ ventral root activity and membrane current of phrenic motoneuron did not fully recover.

mechanism underlying adenosine action by examining the relative contribution of pre- and postsynaptic effects using analysis of changes in the frequency and amplitude of spontaneous or miniature EPSCs.

A preliminary report of this work has been published in abstract form (Dong et al., 1993).

\section{Materials and Methods}

En bloc preparation. Experiments were performed on an in vitro preparation of hrainstem and spinal cord from neonatal rat. Details of the preparation have been previously described (Smith and Feldman, 1987: Liu et al., 1990). In brief, the brainstem and cervical spinal cord were isolated from $06 \mathrm{~d}$ old ether-anesthetized Sprague-Dawley rats. The en bloc neuraxis was then pinned down with ventral surface upward on Sylgard resin in a recording chamber and continuously superfused with physiological Krebs solution (in IIIM: $128 \mathrm{NaCl}, 3 \mathrm{KCl}, 1.5 \mathrm{CaCl}_{2}, 1.0$ $\mathrm{MgSO}_{4}, 21 \mathrm{NaHCO}_{3}, 0.5 \mathrm{NaH}_{2} \mathrm{PO}_{4}, 30$ D-glucose), equilibrated with $95 \% \mathrm{O}_{2} / 5 \% \mathrm{CO}_{2}$. The bath temperature was gradually raised from 18$20^{\circ} \mathrm{C}$ (for isolation) to $25-26^{\circ} \mathrm{C}$ before recording.

Electrophysiology. Respiratory activity was recorded with suction electrodes from the $C_{4}$ ventral root, which contains phrenic motoneuronal axons, and sometimes simultaneously from cranial nerves ( $\mathrm{X}$, XII). Signals were amplified (Grass P51 1 K, Grass Instruments, Quincy, MA), rectified, and low-pass filtered (Paynter filter, $\tau=15 \mathrm{msec}$ ).

Electrodes for whole-cell patch-clamp recordings were pulled from aluminosilicate glass (A-M Systems Inc., Everett, WA) with tip size $\sim 2$ $\mu \mathrm{m}$ and resistance $3.55 \mathrm{M} \Omega$ when filled with the solution containing (in $\mathrm{mM}$ ) $120 \mathrm{~K}^{+}$-gluconate, $1 \mathrm{CaCl}_{2}, 5 \mathrm{NaCl}, 10 \mathrm{~N}$-2-hydroxyethylpiperazine- $N^{\prime}$-2-ethanesulfonic acid (HEPES), 2 ATP (magnesium salt), 10 bis-(o-aminophenoxy)- $N, N, N^{\prime}, N^{\prime}$-tetraacetic acid (BAPTA) (tetrapotassium salt), pH 7.3 adjusted by KOH. Successful patch recording was assured by the initial formation of gigaohm seal $(2-10 \mathrm{G} \Omega)$ and low access resistance $(8-15 \mathrm{M} \Omega$ ). Series resistance was monitored during the experiment, and data were discarded if large increases occurred during the course of the recording. Although series resistance was not compensated, the resultant error should not affect our data qualitatively, since the test drugs showed no significant effect on phrenic motoneuron membrane conductance at the membrane potential of -5 to $-8.5 \mathrm{mV}$ (see Results). Cells were voltage clamped at the end-expiratory potentials of -60 to $-75 \mathrm{mV}$. Data obtained from cells displaying fast $\mathrm{Na}^{\prime}$ currents during inspiration (indicative of poor voltage control over the inspiratory-modulated synaptic current) were not included in the analysis. Signals were amplified with a patch-clamp amplifier (Axopatch ID, Axon Instruments, Foster, CA), and fillered at 2-5 kHz (Bessel filter).

Current-voltage relationships were obtained by applying a series of command voltage pulses ( $100 \mathrm{msec}$ width, $2 \mathrm{~Hz}$ frequency) controlled by a computer (VAX 3200, Digital Equipment, Maynard, MA). Neuron input resistance was calculated from the slope of a least-squares regression line fitted to the data.

Neurons subjected to experimental measurements and data analysis satistied criteria previously described (Liu et al., 1990; Lindsay and Feldman, 1993). Briefly, these neurons had resting membrane potentials of at least $-60 \mathrm{mV}$ and displayed rhythmic synaptic drive currents in synchrony with the inspiratory burst activity on the $C_{4}$ ventral root. These neurons were located at intermediate laterality and 130-300 $\mu \mathrm{m}$ deep from the ventral surface at $\mathrm{C}_{4}$ segment, consistent with the location of the phrenic motoneuron pool in neonatal rats (Lindsay et al., 1991). Moreover, their intrinsic properties, such as membrane capacitance and resistance, werc consistent with the measurements made in neurons identified as phrenic motoneurons by antidromic activation. In each experiment, only one neuron was studied because of the difficulty in removing applied drugs.

Pharmacological substances and application. The drugs used in our experiments included $\mathrm{N}^{6}$-cyclopentyladenosine [CPA; Research Biochemicals (RBI), Natick, MA; 5-100 $\mathrm{M}], 8$-cyclopentyltheophylline (CPT; RBI; 10-100 $\mu \mathrm{M}$ ), 3-isobutyl-1-methylxanthine (IBMX; RBI; 10-100 $\mu \mathrm{M}$ ), 6-cyano-7-nitroquinoxaline-2,3-dione (CNQX; Tocris Neuramin, Bristol, UK; 10-50 $\mu \mathrm{M}$ ), tetrodotoxin (TTX; Sigma, St. Louis, $\mathrm{MO} ; 1 \mu \mathrm{M}$ ), and L-glutamate (L-Glu; Sigma; $0.5-1 \mathrm{mM}$ ).

Drugs were added to the spinal cord bath and/or applied locally via a glass pipette over the spinal cord region containing the phrenic motoneuron pool. Bath application was used to determine the minimum concentrations required for drug action and to perform dose-response tests. When this drug administration technique was used, the bath chamber was partitioned into two compartments at the level of the spinomedullary junction by a transverse petroleum jelly (Vaseline) barrier across the neuraxis. This allowed selective drug application to the spinal cord so as to affect synaptic transmission at the spinal level without disturbing processes at the brainstem level, where the descending inspiratory motor drive originates. Drugs were added to the spinal compartment at concentrations starting from the minimum necessary to induce a clear change in $\mathrm{C}_{4}$ root activity, and $6-8 \mathrm{~min}$ was allowed for equilibrium. For the dose-response tests with drugs with long-lasting effects, a cumulative dose regime was used to determine the effect of increasing concentration; the interval between applications was typically $10-12 \mathrm{~min}$.

Vaseline, necessary for partition, often caused difficulty in obtaining good seals for patch recording. Thus, when such recordings were desired, test agents were applied locally in an unpartitioned chamber via pressure ejection from single or multibarrel electrodes positioned proximally to the ventral surface of the spinal cord over the phrenic motoneuron pool (Liu et al., 1990). Each barrel had an orifice of 8-10 $\mu \mathrm{m}$ and was filled with a drug solution or saline (or artificial cerebrospinal fluid, aCSF). Application of drugs was controlled by brief air pressure pulses to the appropriate drug barrel of electrode. Control injection was made by ejecting saline or aCSF solution. 
Figure 2. Depressant effect of CPA on phrenic motoneuron synaptic current. $A$, Reduction of inspiratory-modulated synaptic current $(\sim 68 \%$ of control) after a 3 min local application of $50 \mu \mathrm{M}$ of CPA. B, Greater depression of inspiratory current induced by 100 $\mu \mathrm{M}$ of CPA in another cell. For this cell, peak inspiratory current was reduced to $\sim 50 \%$ of control. Superimposed traces in $A$ and $B$ are the average of six consecutive inspiratory-modulated synaptic currents before and after drug application. $C$, Time course of inspiratory current in response to local application of CPA $(50 \mu \mathrm{M})$. Peak inspiratory current is expressed as the percentage of control value.
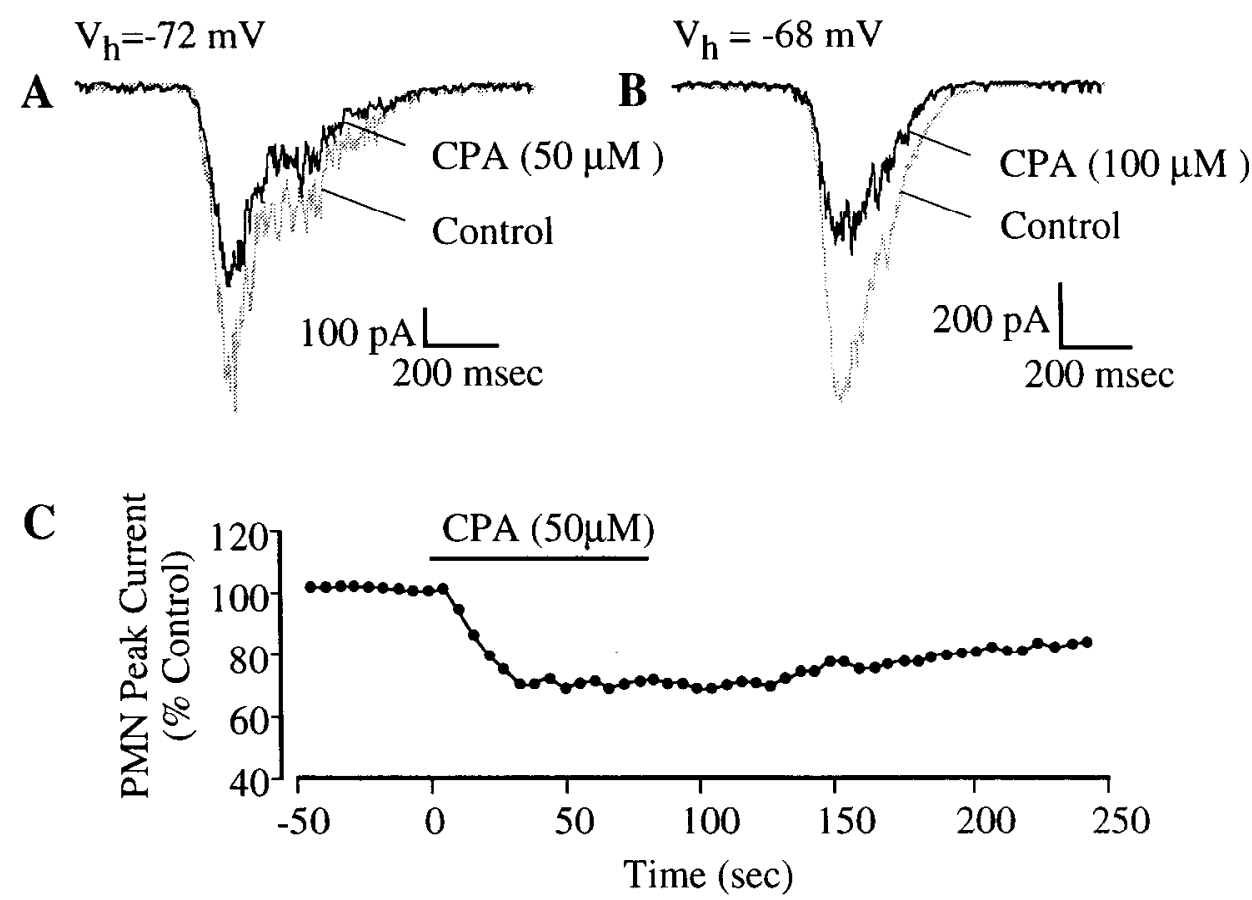
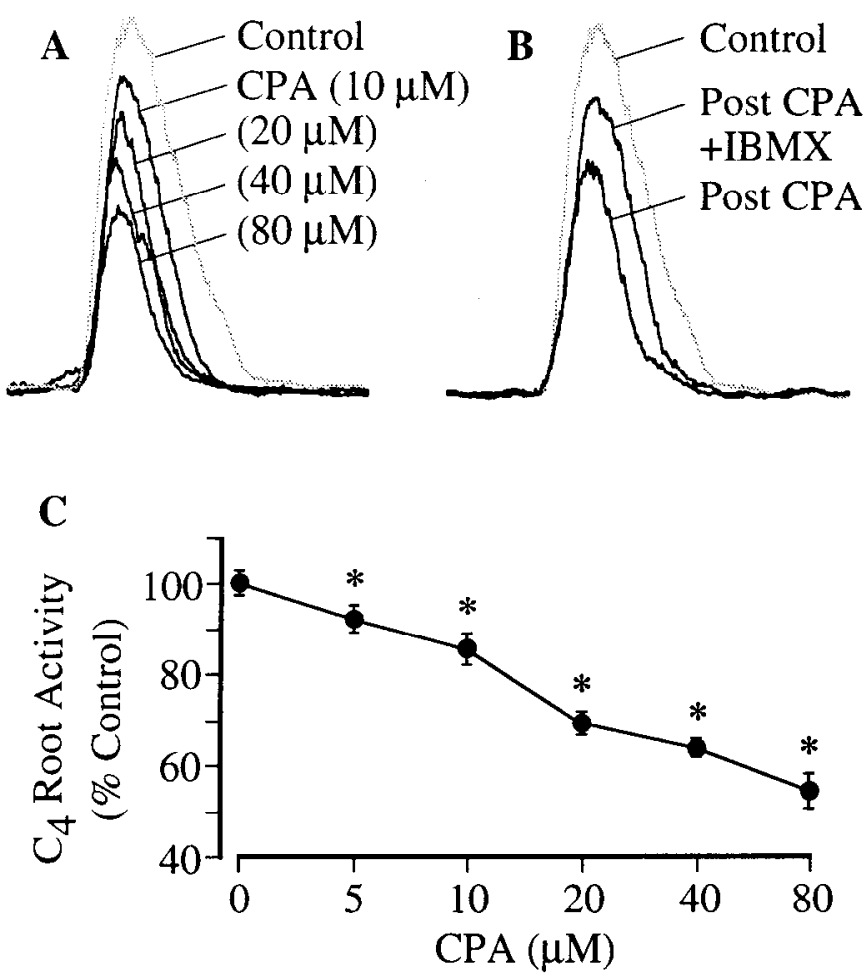

Figure 3. Dose dependency of CPA effects. A, Effects of increasing doses of CPA on inspiratory discharges (integrated) of $C_{4}$ ventral root. Each trace is the average of 10 successive inspiratory discharges obtained after an 8-10 min equilibration time at each concentration. $B$, Long-lasting effects of CPA subsequent to termination of CPA $(80 \mu \mathrm{M})$ application. Following $\mathrm{I} \mathrm{hr}$ of drug washout, only $\sim 25 \%$ recovery from drug effect was obtained. Addition of IBMX $(50 \mu \mathrm{M})$ partially reversed the CPA effect and increased $C_{4}$ activity by $\sim 60 \%$ of the reduction. $C$, Dose-effect relationship of CPA on $\mathrm{C}_{4}$ root activity. The average peak amplitudes obtained from 10 successive $\mathrm{C}_{4}$ root inspiratory discharges (integrated) at each concentration were pooled from six preparations. Error bars are SEM. Asterisk, significant difference $(p<0.05, t$ test) from control values.
In experiments examining drug specificity with $\mathrm{C}_{4}$ root recording, both bath and local techniques were used for applying antagonist and agonist respectively. After the effect of a locally applied agonist was examined, the antagonist was added to the spinal compartment and then the agonist was tested again. When such tests were desired but a partition could not be used with whole-cell recording, multibarrel electrodes were used to deliver test drugs locally. Thus, the application of antagonist began at least 2 min prior to agonist application and continued during the agonist test. The observed change due to a test drug acting at a spinal site rather than at a supraspinal site was indicated by unchanged respiratory rate recorded from $\mathrm{C}_{4}$ root and unchanged amplitude recorded from cranial nerves (X, XII).

Data acquisition and analysis. Data were recorded on videotape via pulse code modulation (Vetter model 3000 , A. R. Vetter Co., Rebersburg, PA; sampled at $10-40 \mathrm{kHz}$ per channel) for off-line analysis. Selected segments of records were digitized at $5-25 \mathrm{kHz}$ using an analog-to-digital converter and stored on a Vaxstation 3200 computer disk for subsequent computer-aided analysis.

For analysis of changes of the respiratory drive, the average values of peak amplitude and area under the envelope of inspiratory-modulated synaptic current or integrated $\mathrm{C}_{4}$ ventral root discharges were computed from respiratory cycles before and following drug application. Statistical values are reported as means \pm SEM. Differences between means were assessed by Student's $t$ test and a value of $p<0.05$ was considered significant.

For analysis of perturbations of frequency and amplitudes of spontaneous EPSCs during expiratory period and miniature EPSCs, the data were first filtered using a Wiener (optimal) filter (Press et al., 1989; Barkat, 1991), which greatly attenuates background noise without significantly affecting the characteristics of the original signal (Liu and Feldman, 1992). Events were then detected using a threshold detector. The amplitude threshold was adjustable and held constant for a given experiment. All detected EPSCs were then subject to analysis. For each condition, interval and amplitude distribution and cumulative probability distribution histograms were constructed. Statistical significance for the difference between distributions was assessed by the KolmogorovSmirnov test (Van der Kloot, 1991) and a value of $p<0.05$ was considered significant.

\section{Results}

Spontaneous rhythmic activity of spinal respiratory motoneurons was examined by extracellular recordings from the spinal ventral $\mathrm{C}_{4}$ roots that contain phrenic motoneuron axons and whole-cell 


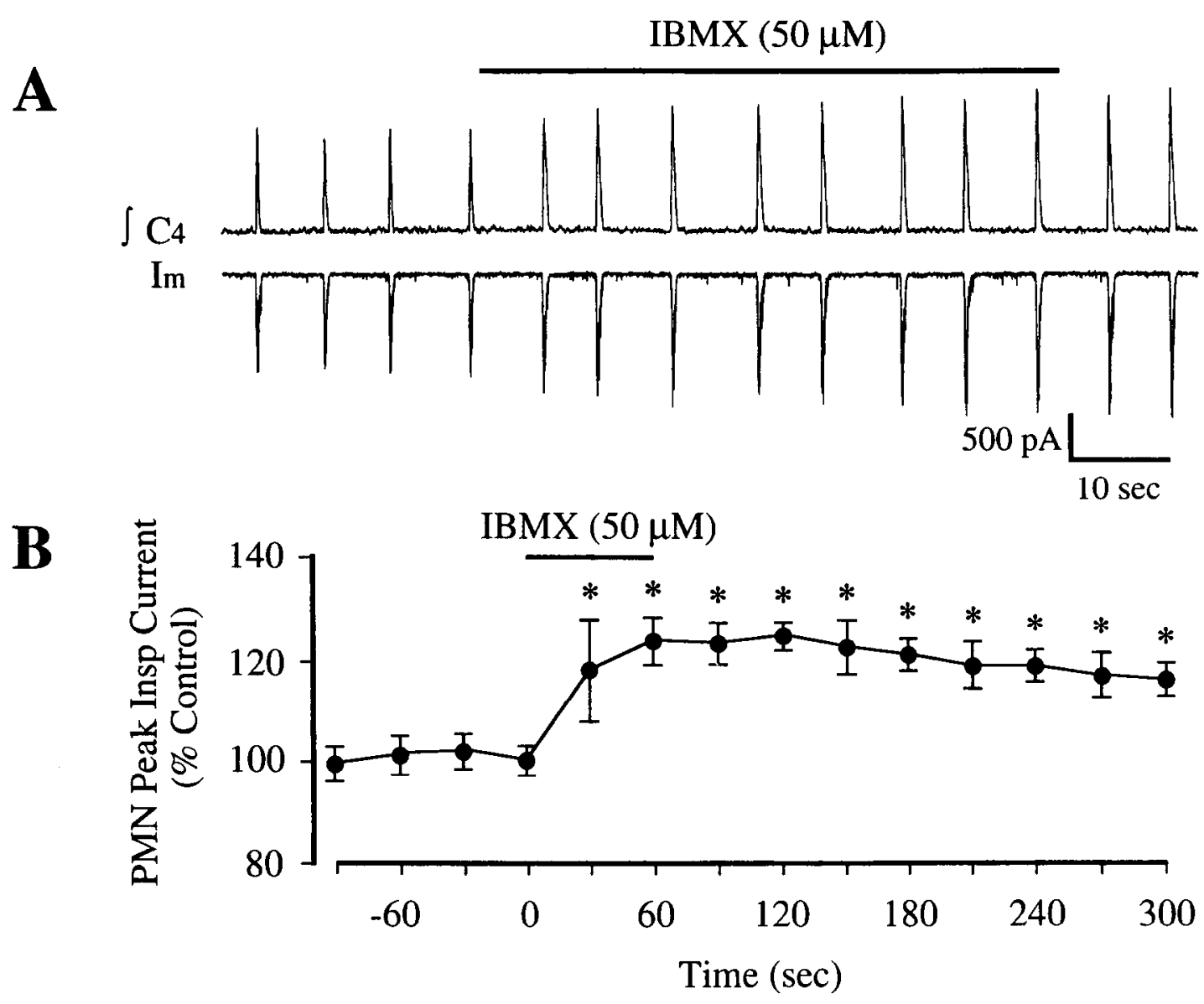

Figure 4. Augmentation of spinal respiratory activity by adenosine receptor antagonist IBMX. $A$, Increase of inspiratory-modulated $\mathrm{C}_{4}$ root activity $(\sqrt{C} 4)$ and phrenic motoneuron synaptic current $(\mathrm{Im})$ by local application of adenosine receptor antagonist IBMX. $B$, Mean increase and time course of inspiratory currents of phrenic motoneuron $(n=5)$ response to local application of IBMX $(50 \mu M)$. Mean amplitudes $(n=5)$ were computed from the average of peak amplitudes over successive $30 \mathrm{sec}$ intervals relative to the onset of drug application in each cell. The peak inspiratory current is expressed as the percentage of control value. Error bars are SEM. Asterisk, significant difference $(p<0.05 ; t$ test) from control values.

voltage-clamp recordings from phrenic motoneurons (Fig. 1, left). The periodic discharge of the $\mathrm{C}_{4}$ root occurred at a frequency of $6-11 / \mathrm{min}$. Each burst consisted of synchronized population discharge of spinal respiratory motoneurons with a duration of $400-700 \mathrm{msec}$.

Phrenic motoneurons $(n=14)$ received rhythmic inputs that generated large EPSCs during the inspiratory phase and small EPSCs at irregular intervals during the expiratory period (Fig. 1; see also Fig. $6 A, B$ ). The inspiratory-modulated synaptic current had a fast rising phase $(-50 \mathrm{msec})$ to peak followed by a slower declining phase $(400-700 \mathrm{msec})$. The peak amplitude of the inspiratory-modulated synaptic current was $0.8-2.5 \mathrm{nA}$ when the membrane potentials were clamped at the end-expiratory potentials of -60 to $-75 \mathrm{mV}$.

\section{Adenosine receptor agonist decreases inspiratory drive to phrenic motoneurons}

Local application of the adenosine analog CPA $(25-100 \mu \mathrm{M})$ over the phrenic motoneuron pool reduced the inspiratory discharge of $\mathrm{C}_{4}$ ventral roots without affecting the respiratory frequency (Fig. 1, $\int \mathrm{C}_{4}, \mathrm{C}_{4}$ ). Pooled data from 11 preparations show that CPA $(50 \mu \mathrm{M})$ significantly decreased peak amplitude of integrated $\mathrm{C}_{4}$ root discharge to $71 \pm 9 \%$ (mean $\pm \mathrm{SEM}$ ) of control. The respiratory frequency $(102 \pm 4 \%$ of control) was not altered.
Concurrent with the depression of $\mathrm{C}_{4}$ root activity, inspiratory-modulated postsynaptic currents $\left(I_{m}\right)$ of phrenic motoneurons $(n=14)$ were reduced by CPA (Figs. 1, 2). Local application of CPA $(50 \mu \mathrm{M})$ significantly decreased the peak inspiratory current to $74 \pm 6 \%$ and the area under the current envelope to $75 \pm 7 \%$ of control values in six cells with the membrane potentials clamped at the end-expiratory potentials. No detectable changes were induced in steady-state membrane current during the expiratory phase. The response to CPA began by the next inspiratory cycle following pressure ejection and took less than $30 \mathrm{sec}$ to peak (Fig. $2 C$ ). The effect of CPA was long-lasting (Figs. 1, 2C, 3B), only a small degree of recovery was obtained even 1 hour after washout (Figs. 1, 3B), and full recovery was never seen. Application of the adenosine receptor antagonist IBMX following CPA washout partially reversed CPA effect (Fig. 3B).

CPA reduced phrenic motor output in a dose-dependent manner in tests where the drug was added to the spinal compartment of a partitioned chamber and $\mathrm{C}_{4}$ root activity was monitored. As CPA is difficult to completely wash out, a cumulative dose regime was used to determine the effect of increasing concentration (10-12 min between applications). Figure $3 A$ illustrates the graded reduction of $\mathrm{C}_{4}$ root activity in response to increments of CPA concentration. The dose-effect relationship for CPA on $\mathrm{C}_{4}$ root activity $(n=6)$ is illustrated in Figure $3 C$. A dose- 
A

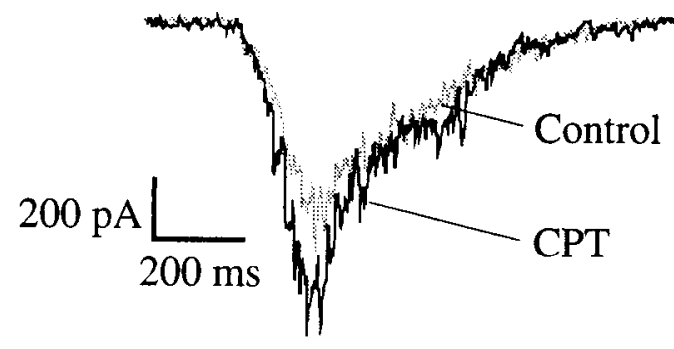

B

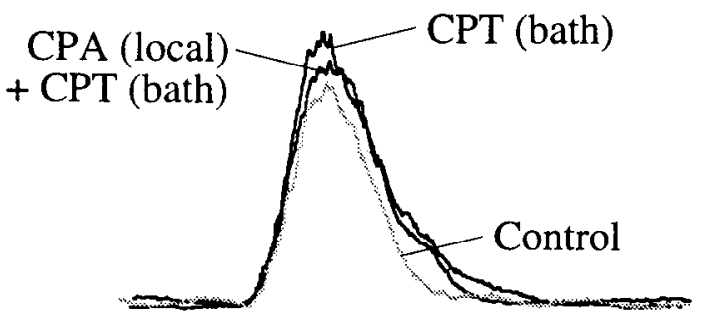

Figure 5. Adenosine $A$ receptor modulation of inspiratory drive transmission to phrenic motoneurons. A, Enhancement of inspiratory synaptic current of a phrenic motoneuron after a $3 \mathrm{~min}$ local application of CPT $(100 \mu \mathrm{M})$, a selective $A_{1}$ receptor antagonist. Traces are the average of six successive inspiratory currents before and after drug application, respectively. $B$, Effects of CPT $(50 \mu \mathrm{M}$, bath applied) on inspiratory discharges (integrated) of $\mathrm{C}_{4}$ ventral root and on the action of locally applied CPA $(100 \mu \mathrm{M})$. Each trace is the average of $10 \mathrm{in}$ tegrated inspiratory discharges.

dependent decrease was also observed when CPA was tested on synaptic currents of phrenic motoneurons. Local application of $100 \mu \mathrm{M}$ CPA caused a greater decrease in inspiratory-modulated synaptic current than $50 \mu \mathrm{M}$ CPA (Fig. $2 A, B$ ).

\section{Presence of endogenous adenosine receptor activation in phrenic motoneuron pool}

To examine whether endogenous adenosine activates receptors in the phrenic motoneuron pool, we tested the effects of an antagonist (IBMX) on respiratory activity in $\mathrm{C}_{4}$ roots and phrenic motoneurons. When applied locally over the phrenic motoneuron pool, IBMX $(50 \mu \mathrm{M})$ significantly increased the inspiratory discharge of $\mathrm{C}_{4}$ roots (Fig. $4 A, \int \mathrm{C}_{4}$ ) by $23 \pm 15 \%$ above control $(n=7)$. The difference was significant $(p<0.05)$. No change in respiratory rate was observed. Concurrent with the increase of $\mathrm{C}_{4}$ root activity, inspiratory-modulated synaptic currents of phrenic motoneurons were enhanced by IBMX (Fig. 4A, Im). Pooled data for the effect of IBMX on inspiratory currents at $50 \mu \mathrm{M}$ from five cells are shown in Figure $4 B$. The time course for recovery was so long that only about $50 \%$ recovery was obtained at $20 \mathrm{~min}$ after drug washout.

\section{Involvement of $A$, receptor subtype}

To investigate the possible involvement of $A_{1}$ receptors in mediating the action of endogenously released and exogenously applied adenosine, we tested the effects of CPT, a selective $A_{1}$ receptor antagonist (Bruns et al., 1986). Both inspiratory-modulated synaptic currents of phrenic motoneurons (Fig. 5A) and the activity of $\mathrm{C}_{4}$ ventral roots (Fig. $5 B$ ) were enhanced by CPT. The mean increases of synaptic current and $\mathrm{C}_{4}$ root activity by local CPT $(50 \mu \mathrm{M})$ were $19 \pm 11 \%(n=4)$ and $29 \pm 17 \%(n$
$=7$ ) of control, respectively. Both changes were significant. Moreover, in the presence of CPT in the spinal bath, CPA, when applied locally over the phrenic motoneuron pool, failed to decrease $\mathrm{C}_{4}$ root activity below control value (Fig. $5 B$ ).

Presynaptic action of adenosine receptor in decreasing frequency of synaptic events

To investigate the relative pre- and postsynaptic contributions to the adenosine-induced decrease in excitatory synaptic transmission to phrenic motoneurons, we analyzed the frequency and amplitude distribution of spontaneous unitary EPSCs. We could not perform this analysis during inspiration since there were typically too many overlapping unitary EPSCs to analyze. During the expiratory phase, however, phrenic motoneurons exhibited numerous small discrete EPSCs (Figs. 1, 6A,B; see also Liu and Feldman, 1992). For the purpose of this analysis, drugs were applied locally over the phrenic motoneuron pool for 7-10 min, to obtain a sufficient number of EPSCs for analysis. Data were collected from a 5-10 min control period and from the period of drug application. The time interval between successive EPSCs and the amplitudes were used to construct cumulative interval and amplitude histograms (e.g., Fig. 6C,D).

Local application of CPA over the phrenic motoneuron pool significantly decreased the frequency of EPSCs during expiratory phase, as indicated by the shift of the cumulative interval histogram toward longer interval values (Fig. 6C) in six of six cells. In contrast, the amplitude distribution was only slightly affected (Fig. $6 D$ ). CPA $(50 \mu \mathrm{M})$ induced a $28 \pm 13 \%$ reduction in the mean frequency of EPSCs, whereas the mean amplitude of EPSCs in the presence of CPA was $93 \pm 6 \%(n=6)$ of the control value.

To determine whether the observed effects of CPA were a consequence of a direct action on synapses onto phrenic motoneurons or an indirect action on putative interneurons in the vicinity relaying inputs to phrenic nucleus, the effects of CPA were examined following synaptic isolation of phrenic motoneurons by blocking presynaptic $\mathrm{Na}^{+}$-dependent action potentials with bath application of TTX $(1 \mu \mathrm{M})$. In the presence of TTX, phrenic motoneurons exhibited miniature EPSCs (Fig. 7A). Addition of CPA $(10 \mu \mathrm{M})$ to the bath produced a $30 \pm$ $12 \%(n=4)$ reduction in miniature EPSC frequency (Fig. $7 B$ ), consistent with the results obtained from the analysis on EPSCs during the expiratory phase. Figure $7 C$ shows the frequency change of a representative cell. There was, however, no significant change in the miniature EPSC amplitude distribution (Fig. $7 D)$.

\section{Lack of effects on postsynaptic membrane properties near resting potentials}

To examine the possible postsynaptic actions of adenosine that may contribute to the observed effect on inspiratory-modulated synaptic current of phrenic motoneurons, the postsynaptic response to exogenous glutamate and the membrane currentvoltage $(I-V)$ relationship were tested before and following the addition of CPA in phrenic motoneurons isolated by TTX (Fig. 8).

Brief local application $(1 \mathrm{sec})$ of $1 \mathrm{~mm}$ glutamate produced an inward current with peak amplitude $130-180 \mathrm{pA}(n=7$ cells). Glutamate-induced currents were attenuated by locally applied CNQX $(20 \mu \mathrm{M})$ but were unaffected by bath application of $25 \mu \mathrm{M}$ of CPA (Fig. 8A). Furthermore, bath application of CPA $(10-50 \mu \mathrm{M})$ did not induce any significant change in 
$\mathbf{A}$

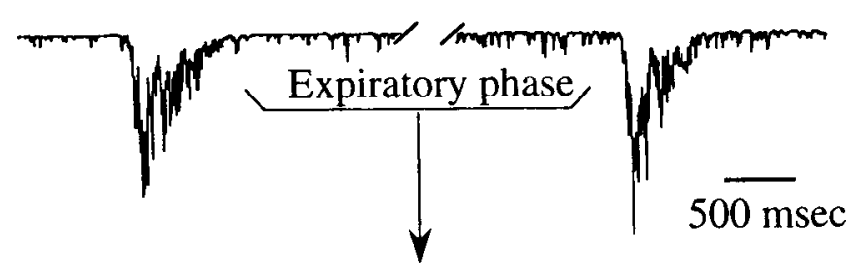

Control

B

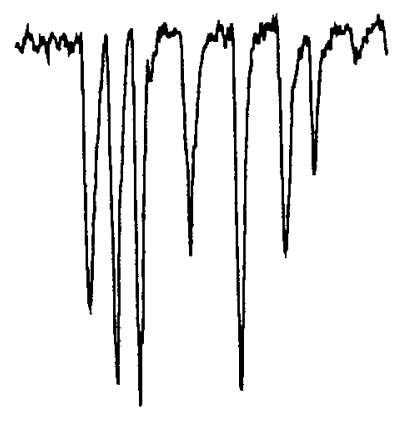

$\mathrm{CPA}(50 \mu \mathrm{M})$

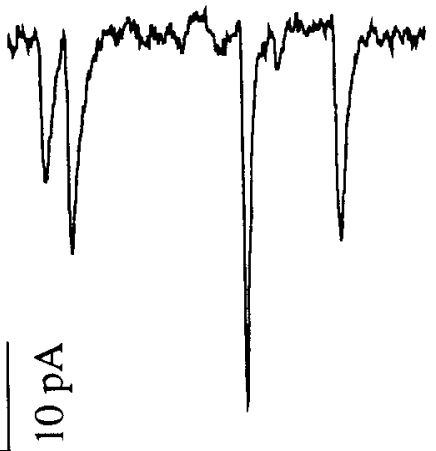

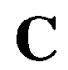

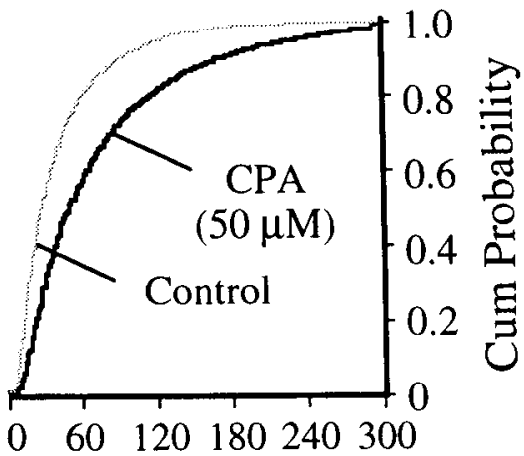

EPSC Intvl (ms)
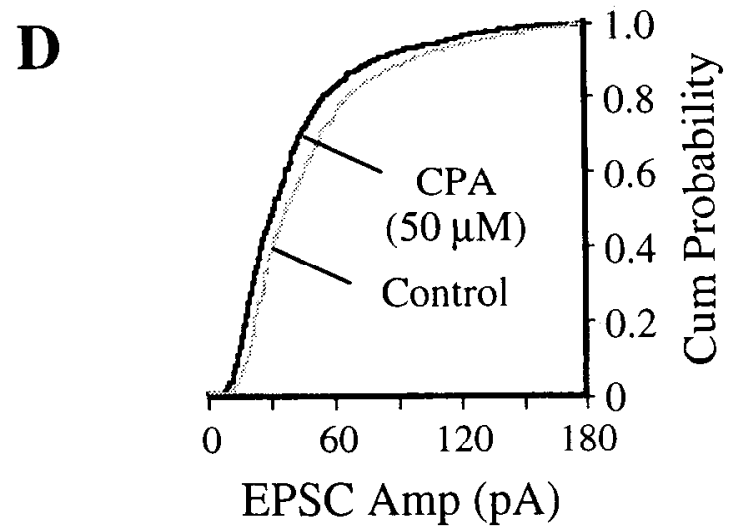

Figure 6. Effects of CPA on frequency and amplitude of spontaneous EPSCs during expiratory phase. A, Raw trace of membrane current showing spontaneous EPSCs during expiratory phase $\left(V_{h}=-69 \mathrm{mV}\right) . B$, Sample recording of spontaneous EPSCs from the cell represented in $A$ before and after application of CPA. Note that EPSC frequency was decreased. $C$, Cumulative interval $($ Intvl $)$ histograms of EPSCs from the cell represented in A before (3934 events, gray curve) and after (3182 events, black curve) local application of CPA (50 $\mu$ M). CPA induced a significant ( $p<$ 0.001 ) rightward shift in cumulative distribution of EPSC intervals (i.e., the decrease in EPSC frequency). D. Cumulative amplitude (Amp) histograms of EPSCs from the same data sets in $C$. CPA induced a small but significant $(p<0.001)$ leftward shift in cumulative distribution of EPSC amplitudes. Statistical significance for the difference between distributions was assessed by the Kolmogorov-Smirnov test.

membrane input resistance at the membrane potentials of -45 to $-85 \mathrm{mV}$ ( $n=8$ cells; Fig. $8 B$ ). In five of eight neurons, however, CPA $(25 \mu \mathrm{M})$ induced a slight but consistent increase in membrane resistance at potentials more depolarized than -5 $\mathrm{mV}$ (data not shown). This suggests a postsynaptic action of $A_{1}$ receptors on voltage-gated ion channels, but we did not further investigate this observation.

\section{Discussion}

Our principal finding is that adenosine acting at $A_{\text {, receptors }}$ can modulate the transmission of inspiratory drive to phrenic motoneurons. Exogenous application of the adenosine $A_{1}$ receptor agonist CPA induced a decrease in both inspiratorymodulated synaptic currents and frequency of spontaneous EPSCs in phrenic motoneurons; this effect was blocked by adenosine receptor antagonists IBMX or CPT. In our in vitro preparation, $A_{1}$ receptor antagonism increased inspiratorymodulated synaptic currents of phrenic motoneurons, suggesting that there was endogenous activation of adenosine receptors that reduced synaptic transmission to phrenic motoneurons. Activation of adenosine $A_{1}$ receptors did not change either the steady-state membrane current or the membrane input resistance of phrenic motoneurons. Inward current induced by exogenously applied glutamate was also unaffected by CPA. Furthermore, CPA produced a significant decrease in the frequency of both spontaneous and miniature EPSCs (which are glutamatergic; Liu et al., 1990). We propose that the reduction of inspiratory drive by adenosine is mediated by $A_{1}$ receptors on the presynaptic terminals of bulbospinal inspiratory neurons onto phrenic motoneurons.

\section{Adenosine $A$, receptors decrease transmission of inspiratory drive to phrenic motoneurons}

The findings that inspiratory-modulated $\mathrm{C}_{4}$ root activity and phrenic motoneuron synaptic current are depressed by an adenosine $A_{1}$ receptor agonist and enhanced by antagonists indicate that $A_{1}$ reccptors reduce bulbospinal synaptic transmission of inspiratory drive to phrenic motoneurons. The enhancement induced by the receptor antagonists suggests that, in this in vitro preparation, bulbospinal transmission is already attenuated by endogenous activation of adenosine receptors. We initially based this conclusion on the enhancement of inspiratory drive by IBMX; however, IBMX can have other effects in addition to its receptor antagonism (Phillis and $\mathrm{Wu}, 1981$ ). In particular, IBMX can increase brain cAMP levels by inhibiting phosphodiesterase activity (Smellie et al., 1979; Miot et al., 1984; Chavez-Noriega and Stevens, 1994). Thus, the data with IBMX alone are not conclusive as to the role of adenosine receptors. Use of the more specific adenosine $A_{1}$ receptor antagonist, CPT, however, confirmed the results with IBMX, supporting the conclusion that adenosine is an endogenous neuromodulator within the phrenic motoneuron pool. 


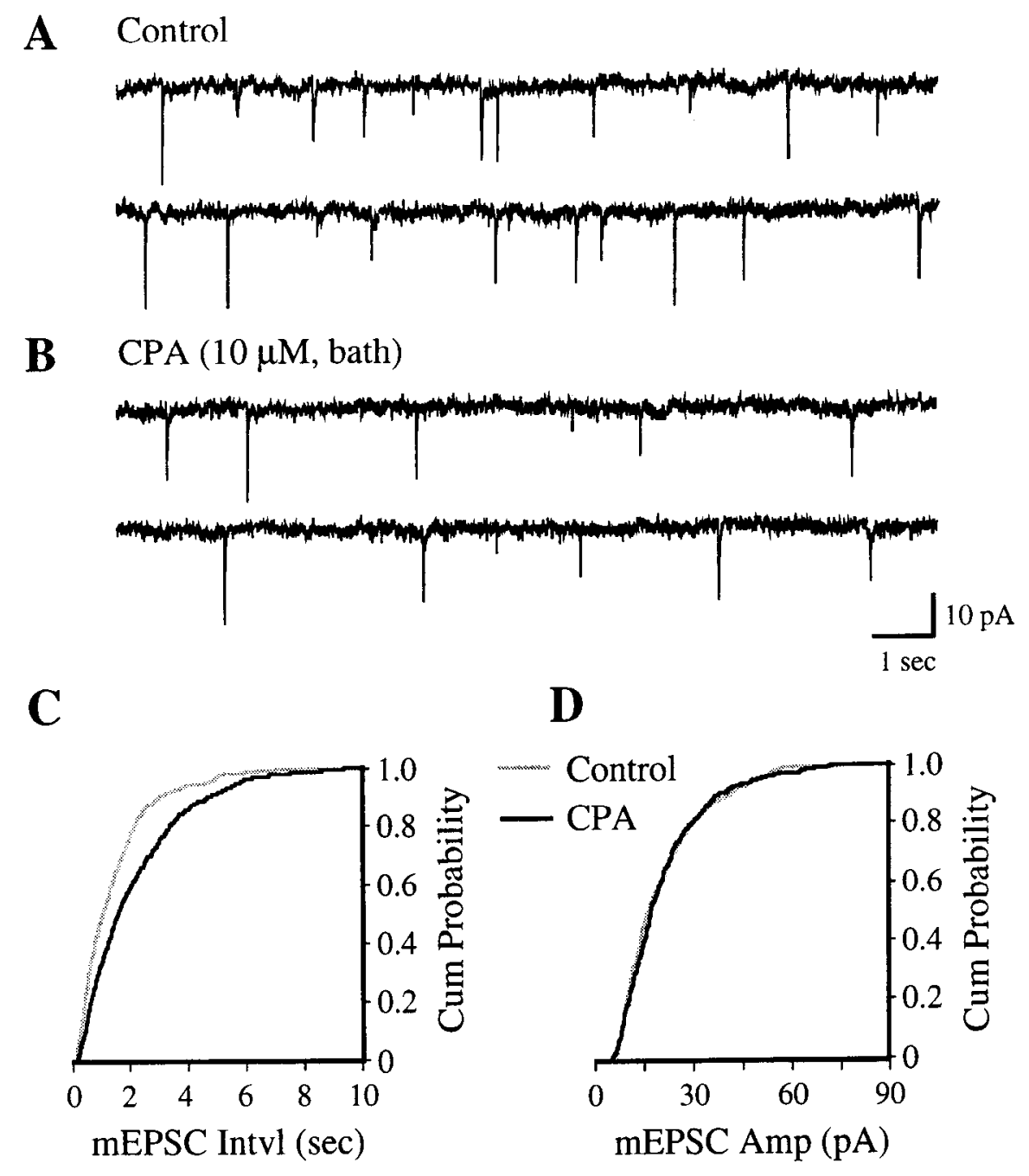
EPSCs (mEPSCs). A, Raw trace showing typical mEPSCs following bath application of TTX $(1 \mu \mathrm{M}) . V_{h}=-72$ mV. $B$, Addition of CPA $(10 \mu \mathrm{M})$ to bath reduced the frequency of $\mathrm{m}$ EPSCs. C, Cumulative interval (Intvl) histograms of mEPSCs from the cell gray curve) and after (637 events, black curve) bath application of CPA $(10 \mu \mathrm{M})$. CPA induced a significant $(p$ $<0.01)$ rightward shift in cumulative distribution of mEPSC intervals (i.e., the decrease in EPSC frequency). $D$, Cumulative amplitude (Amp) histograms of mEPSCs from the same data sets in $C$. Note that there was no significant $(p>0.05)$ difference in the amplitude distributions between control and CPA conditions. Statistical significance for the difference between distributions was assessed by the Kolmo-
Figure 7. Effect of CPA on miniature represented in $A$ before ( 862 events, gorov-Smirnov test.

It is important to note that it is difficult to precisely quantify the effects of adenosine. The modulation of synaptic transmission to phrenic motoneurons may involve a complex cascade of mechanisms mediated by several neuronal modulators (Feldman et al., 1990; Feldman and Smith, 1994) including adenosine. Changes in synaptic transmission induced by adenosine receptor activator or inhibitor could result from the modulation mediated directly by adenosine receptors. Changes may also result from indirect effects on the activity of other modulating systems. For instance, the increased glutamate release following CPT exposure could increase activity of presynaptic $\mathrm{AP}_{4}$-sensitive metabotropic glutamate receptors (Liu et al., 1990; Dong et al., 1994) and attenuate the increased release. Thus, we may have underestimated the CPT enhancement of inspiratory synaptic drive. While these uncontrolled factors cause difficulties in precise quantification of the effects of $\mathrm{A}_{1}$ receptor agonists and antagonists, our data provide clear, qualitative evidence for the involvement of adenosine $A_{1}$ receptors in synaptic transmission of inspiratory drive to phrenic motoneurons.

The adenosine-induced change in phrenic motoneuronal excitability was characterized by a decrease in excitatory synaptic currents without any significant changes in postsynaptic membrane properties. We attribute these effects to actions in the spinal cord, but an action in the brainstem, due to diffusion of drugs from spinal cord to brainstem, must be considered. Direct application of adenosine receptor agonists or antagonists to the brainstem altered respiratory rate (X.-W. Dong and J. L. Feldman, unpublished observations); thus, diffusion of the drugs from the spinal cord to the brainstem should produce a change in rhythm. This was rarely observed, and all such cases were excluded from analysis.

Another possibility for unaltered postsynaptic properties of recorded phrenic motoneurons also needs to be considered, that is, an action on putative spinal cord interneurons relaying the descending inspiratory drive to phrenic motoneurons. This is, however, unlikely because (1) considerable evidence indicates that bulbospinal transmission of respiratory drive to phrenic motoneurons is mediated primarily by a monosynaptic pathway (Ellenberger and Feldman, 1988; Berger et al., 1989; Ellenberger et al., 1990; Lipski et al., 1994); (2) upper cervical $\left(C_{1}-C_{2}\right)$ inspiratory neurons (identified in adult cat; Aoki et al., 1987) do not appear to project to phrenic motoneurons (Lipski and Duffin, 1986); (3) spinal cord interneurons with respiratory-modulated activity at the level of the phrenic nucleus (Davies et al., 1985; Palisses et al., 1989; Bellingham and Lipski, 1990; Grélot et al., 1993; Dong and Feldman, unpublished observations) have never been shown to project to phrenic motoneurons; and (4) when phrenic motoncurons werc isolated by TTX, test drugs continued to affect certain cellular events (e.g., frequency of miniature EPSCs). Drug effects therefore appear to be due to direct action on phrenic motoneurons or impinging presynaptic terminals. 


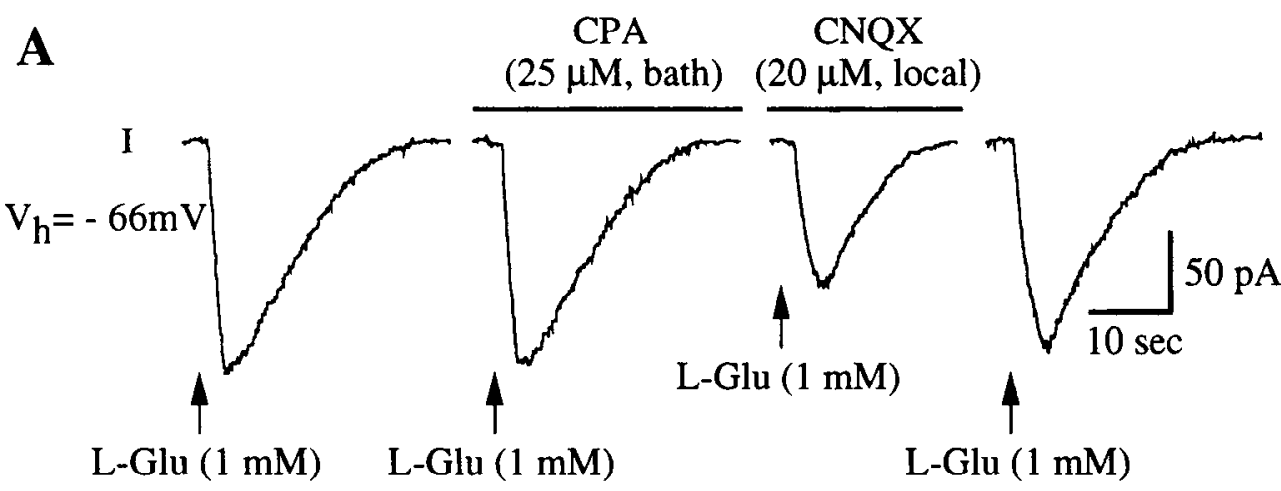

B
Current (nA)

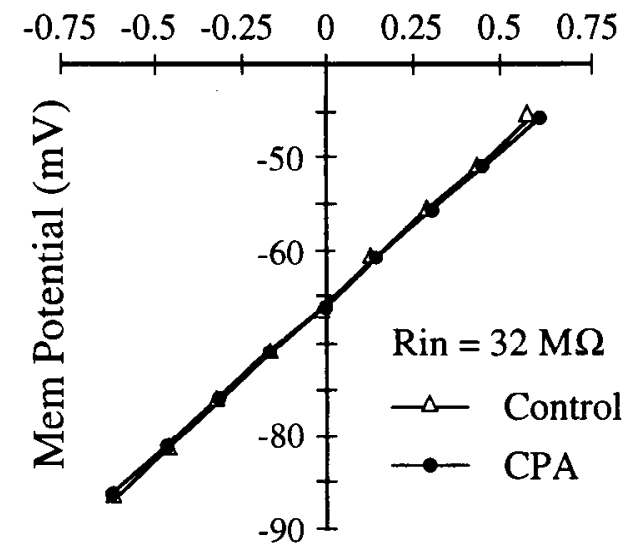

Figure 8. Lack of postsynaptic effect of $A_{1}$ receptors on a phrenic motoneurons near resting potential. $A$, Inward current induced under voltage-clamp conditions by local application of $1 \mathrm{~mm}$ L-glutamate $(L-G l u)$ in the presence and absence of CPA. L-Glu was applied by 1 sec brief ejection from a micropipette. Bath application of CPA (25 $\mu \mathrm{M})$ began $7 \mathrm{~min}$ prior to L-Glu application and continued during the course of I-Glu test. CNQX (20 $\mu$ M) was locally applied 2 min prior to and continued during L-Glu test. Note that CPA has no detectable effect on Glu-induced currents. $B$, Membrane $I-V$ relationship before and after application of CPA (25 $\mu M) . I-V$ relationship was obtained by plotting current change after application of a series of command voltage pulses. Pulse step size, $5 \mathrm{mV}$; pulse width, $100 \mathrm{msec}$; pulse number, 8; pulse frequency, $2 \mathrm{~Hz}$. Steady-state current values ( $2 \mathrm{msec}$ before offset of voltage step) were used to generate $I-$ $V$ plot. Membrane input resistance is determined by the slope of $I-V$ plot. Note that membrane input resistance did not change in the presence of CPA. These experiments were performed in the presence of TTX $(1 \mu \mathrm{M})$ in the bath.
Presynaptic action of adenosine mediates depression of inspiratory drive

Adenosine has both pre- and postsynaptic effects in the CNS. Presynaptically, adenosine inhibits synaptic transmission by decreasing the amount of transmitter released (Kocsis et al., 1984; Malenka and Kocsis, 1988; Prince and Stevens, 1992; Scanziani et al., 1992; Scholz and Miller, 1992). Direct measurements of glutamate release have confirmed that adenosine can diminish stimulation-evoked release of glutamate from brain slice and from cultured neurons (Dolphin and Archer, 1983; Corradetti et al., 1984; Dolphin and Prestwich, 1985). Postsynaptically, adenosine hyperpolarizes cells by increasing a postsynaptic $\mathrm{K}^{+}$conductance (Greene and Haas, 1985; Trussell and Jackson, 1985; Proctor and Dunwiddie, 1987; Gerber et al., 1989). Adenosine also inhibits voltage-dependent $\mathrm{Ca}^{2+}$ channels (MacDonald et al., 1986; Scholz and Miller, 1991; Mynlieff and Beam, 1994).

Our data suggest that presynaptic actions account for the decrease of inspiratory-modulated synaptic current following activation of $A_{1}$ receptors. First, we have investigated the effects of adenosine on three different classes of synaptic events: inspiratory drive, spontaneous EPSCs during expiration, and miniature EPSCs following TTX administration. CPA reduced the frequency of spontaneous EPSCs during the cxpiratory phase, as well as that of miniature EPSCs following the blockage of $\mathrm{Na}^{+}$-dependent action potentials. Because the frequency of miniature EPSCs is dependent upon the probability of transmitter release (Fatt and Katz, 1952; see Redman, 1990), its reduction, and by extension that of spontaneous EPSCs during expiratory phase, indicates a presynaptic action of CPA that affects quantal release of transmitter from presynaptic terminals. Based on the analysis of unitary EPSCs, we concluded that the action of adenosine $A_{1}$ receptors is to block presynaptic release of neurotransmitter. Although events during both inspiration and expiration have similar pharmacology, that is, are due to the release of an EAA acting predominantly at non-NMDA receptors, we have no direct evidence that the presynaptic terminals producing the EPSCs during expiration include those of bulbospinal inspiratory neurons. We presume for the purposes of discussion that the results obtained for unitary EPSCs apply to those occurring during inspiration.

Second, no alterations in postsynaptic membrane properties were produced by the adenosine receptor agonist CPA. The agonist had no detectable effect on the steady-state membrane current during the expiratory phase. The input resistance of phrenic motoneurons was unaltered in the presence of CPA (Fig. 8B). Therefore, the decrease of inspiratory drive current by CPA was not associated with an increase in membrane conductance, which might otherwise cause shunting of synaptic currents.

Third, the sensitivity of phrenic motoneurons to glutamate was not affected by CPA. Our previous studies have established that the transmission of inspiratory drive from bulbospinal neurons to phrenic motoneurons is mediated by an EAA-like substance acting primarily at non-NMDA receptors (Liu et al., 1990). If the decrease of synaptic current was due to CPA reducing the sensitivity of postsynaptic EAA receptors, the inward current induced by exogenously applied glutamate should have also been reduced by CPA. In the presence of TTX, however, 
CPA did not alter the responsiveness of phrenic motoneurons to exogenously applied glutamate (Fig. 8A).

We conclude that adenosine and its analogs depress inspiratory synaptic currents in phrenic motoneurons by activating presynaptic adenosine $A_{1}$ receptors. A postsynaptic action of adenosine affecting phrenic motoneuron excitability cannot be completely excluded. Our observations were made on cells that were voltage clamped at resting membrane potentials under whole-cell patch-clamp conditions. Thus, we could not observe effects on voltage-gated channels. Activation of $A_{1}$ receptors inhibits voltage-gated $\mathrm{N}$-type $\mathrm{Ca}^{2+}$ current in motoneurons (Mynlieff and Beam, 1994) and in hippocampal neurons (Mogul et al., 1993). Moreover, in rat sympathetic neurons, adenosine decreases $\mathrm{Ca}^{2+}$ current in a voltage-dependent manner (Zhu and Ikeda, 1993). We also observed a shift in the $I-V$ relationship curve at higher depolarizing potential after the application of CPA (data not shown), suggesting a postsynaptic action of $A_{\text {, }}$ receptors on voltage-gated ion channels. In addition, under whole-cell patch-clamp conditions, intracellular dialysis could also affect adenosine actions mediated by second messenger systems.

In summary, our study demonstrates the involvement of adenosine $A_{1}$ receptors in regulating respiratory output at the level of the spinal cord by presynaptically modulating bulbospinal synaptic transmission of inspiratory drive to phrenic motoneurons. The presynaptic modulation by adenosine may play an important role in adjusting respiratory input to phrenic motoneurons, and thus regulating respiratory motor output. This mechanism may become more critical in preventing diaphragm from fatigue during high levels of ventilatory drive, such as during extreme exercise, since adenosine levels may increase under these conditions.

\section{References}

Alzheimer C, Kargl L, ten Bruggencate G (1991) Adenosinergic inhibition in hippocampus is mediated by adenosine $\mathrm{A} 1$ receptors very similar to those of peripheral tissues. Eur J Pharmacol 196:313-317.

Aoki M, Fujito Y, Kurosawa Y, Kawasaki H, Kosaka I (1987) Descending inputs to the upper cervical inspiratory neurons from the medullary respiratory neurons and the raphe nuclei in the cat. In: Respiratory muscles and their neuromotor control (Sieck GC, Gandevia SC, Cameron WE, eds), pp 73-82. New York: Raven.

Barkat M (1991) Signal detection and estimation, pp 218-220. Boston: Artech House.

Barraco RA, el-Ridi MR, Parizon M (1990) The adenosine analog, 5'$N$-ethylcarboxamidoadenosine, exerts mixed agonist action on cardiorespiratory parameters in the intact but not decercbrate rat following microinjections into the nucleus tractus solitarius. Brain Res 530 : $54-72$.

Bellingham MC, Lipski J (1990) Respiratory interneurons in the C5 segment of the spinal cord of the cat. Brain Res 533:141-146.

Berger AJ, Dick TE, Jodkowski JS, Viana F (1989) Phrenic motoneurons: descending inputs, electrical properties, and recruitment. In: Chemoreceptors and reflexes in breathing, cellular and molecular aspects (Lahire S, Forster RE II, Davies RO, Pack AI, eds), pp 343350 .

Bissonnette JM, Hohimer AR, Knopp SJ (1991) The effect of centrally administered adenosine on fetal breathing movements. Respir Physiol $84: 273-285$

Bruns RF, Lu GH, Pugsley TA (1986) Characterization of the A2 adenosine receptor labeled by $\left[{ }^{3} \mathrm{H}\right] \mathrm{NECA}$ in rat striatal membranes. Mol Pharmacol 29:331-346.

Chavez-Noriega LE, Stevens CF (1994) Increased transmitter release at excitatory synapses produced by direct activation of adenylate cyclase in rat hippocampal slices. J Neurosei 14:310-317.

Corradetti R, Lo Conte G, Moroni F, Passani MB, Pepeu G (1984) Adenosine decreases aspartate and glutamate release from rat hippocampal slices. Eur J Pharmacol 104:19-26.
Davies JG, Kirkwood PA, Sears TA (1985) The distribution of monosynaptic connexions from inspiratory bulbospinal neurones to inspiratory motoneurones in the cat. J Physiol (Lond) 368:63-87.

Dolphin AC, Archer ER (1983) An adenosine agonist inhibits and a cyclic AMP analogue enhances the release of glutamate but not GABA from slices of rat dentate gyrus. Neurosci Lett 43:49-54.

Dolphin AC, Prestwich SA (1985) Pertussis toxin reverses adenosine inhibition of neuronal glutamate release. Nature 316:148-150.

Dong X-W, Liu G, Feldman JL (1993) Adenosine receptors modulate inspiratory drive to phrenic motoneurons. Soc Neurosci Abstr 19: 1524.

Dong X-W, Morin D, Feldman JL (1994) Metabotropic glutamate receptors attenuate inspiratory-modulated synaptic current in phrenic motoneurons. Soc Neurosci Abstr 20:1714.

Dunwiddie TV (1985) The physiological role of adenosine in the central nervous system. Int Rev Neurobiol 27:63-139.

Dunwiddie TV, Fredholm BB (1989) Adenosine A1 receptors inhibit adenylate cyclase activity and neurotransmitter release and hyperpolarize pyramidal neurons in rat hippocampus. J Pharmacol Exp Ther 249:31-37.

Dunwiddie TV, Iloffer BJ (1980) Adenine nucleotides and synaptic transmission in the in vitro rat hippocampus. Br J Pharmacol 69:5968 .

Ellenberger HH, Feldman JL (1988) Monosynaptic transmission of respiratory drive to phrenic motoneurons from brainstem bulbospinal neurons in rats. J Comp Neurol 269:47-57.

Ellenberger HH, Feldman JL, Goshgarian HG (1990) Ventral respiratory group projections to phrenic motoneurons: electron microscopic evidence for monosynaptic connections. I Comp Neurol 302:707714.

Ellenberger HH, Vera PL, Feldman JL, Holets VR (1992) Multiple putative neuromessengers inputs to phrenic motoneurons in rat. $\mathbf{J}$ Chem Neuroanat 5:375-382.

Fatt P, Katz B (1952) Spontaneous subthreshold activity at motor nerve endings. J Physiol (Lond) 117:109-128.

Feldman JL, Smith JC (1989) Cellular mechanisms underlying modulation of breathing pattern in mammals. Ann NY Acad Sci 563: 114-130.

Feldman JL, Smith JC (1994) Neural control of respiratory pattern in mammals: an overview. In: Lung biology in health and disease: regulation of breathing (Dempsey JA, Pack AI, eds), pp 39-69. New York: Dekker.

Feldman JL, Smith JC, Ellenberger HH, Connelly CA, Liu G, Greer JJ, Lindsay AD, Otto MR (1990) Neurogenesis of respiratory rhythm and pattern: emerging concepts. Am J Physiol 259:R879-R886.

Gerber U, Greene RW, Haas HL, Stevens DR (1989) Characterization of inhibition mediated by adenosine in the hippocampus of the rat in vitro. J Physiol (Lond) 417:567-578.

Greene RW, Haas HL (1985) Adenosine actions on CAl pyramidal neurones in rat hippocampal slices. J Physiol (Lond) 366:119-127.

Greene RW, Haas HL (1991) The electrophysiology of adenosine in the mammalian central nervous system. Prog Neurobiol 36:329-341.

Grélot L, Milano S, Portillo F, Miller AD (1993) Respiratory interneurons of the lower cervical (C4-C5) cord: membrane potential changes during fictive coughing, vomiting, and swallowing in the decerebrate cat. Pfluegers Arch Eur J Physiol 425:313-320.

Kocsis JD, Eng DL, Bhisitkul RB (1984) Adenosine sclectively blocks parallel-fiber-mediated synaptic potentials in rat cerebellar cortex. Proc Natl Acad Sci USA 81:6531-6534.

Lagercrantz H, Yamamoto Y, Fredholm BB, Prabhakar NR, von Euler C (1984) Adenosine analogues depress ventilation in rabbit neonates. Theophylline stimulation of respiration via adenosine receptors? Pediatric Res 18:387-390.

Lambert NA, Teyler TJ (1991) Adenosine depresses excitatory but not fast inhibitory synaptic transmission in area $\mathrm{CA} 1$ of the rat hippocampus. Neurosci Lett 122:50-52.

Lindsay AD, Feldman JL (1993) Modulation of respiratory activity of neonatal rat phrenic motoneurones by serotonin. J Physiol (Lond) 461:213-233.

Lindsay AD, Greer JJ, Feldman JL (1991) Phrenic motoneuron morphology in the neonatal rat. J Comp Neurol 308:169-179.

Lipski J, Duffin J (1986) An electrophysiological investigation of propriospinal inspiratory neurons in the upper cervical cord of the cat. Exp Brain Res 61:625-637.

Lipski J, Zhang X, Kruszewska B, Kanjhan R (1994) Morphological 
study of long axonal projections of ventral medullary inspiratory neurons in the rat. Brain Res 640:171-184.

Liu G, Feldman JL (1992) Quantal synaptic transmission in phrenic motor nucleus. J Neurophysiol 68:1468-1471.

Liu G, Feldman JL, Smith JC (1990) Excitatory amino acid-mediated transmission of inspiratory drive to phrenic motoneurons. I Neurophysiol 64:423-436.

Londos C, Cooper DM, Wolff J (1980) Subclasses of external adenosine receptors. Proc Natl Acad Sci USA 77:2551-2554.

MacDonald RL, Skerritt JH, Werz MA (1986) Adenosine agonists reduce voltage-dependent calcium conductance of mouse sensory neurones in cell culture. J Physiol (Lond) 370:/5-90.

Malenka RC, Kocsis JD (1988) Presynaptic actions of carbachol and adenosine on corticostriatal synaptic transmission studied in vitro. J Neurosci 8:3750-3757.

McCrimmon DR, Smith JC, Feldman JL (1989) Involvement of excitatory amino acids in neurotransmission of inspiratory drive to spinal respiratory motoneurons. J Neurosci 9:1910-1921.

Miot F, Erneux C, Wells JN, Dumont JE (1984) The effects of alkylated xanthines on cyclic AMP accumulation in dog thyroid slices exposed to carbamylcholine. Mol Pharmacol 25:261-266.

Mogul DJ, Adams ME, Fox AP (1993) Differential activation of adenosine receptors decreases $\mathrm{N}$-type but potentiates $\mathrm{P}$-type $\mathrm{Ca}^{2+}$ current in hippocampal CA3 neurons. Neuron 10:327-334.

Mynlieff M, Beam KG (1994) Adenosine acting at an $A_{1}$ receptor decreases $\mathrm{N}$-type calcium current in mouse motoneurons. J Neurosci 14:3628-3634.

Nicoll RA, Malenka RC, Kauer JA (1990) Functional comparison of neurotransmitter receptor subtypes in mammalian central nervous system. Physiol Rev 70:513-565.

Okada Y, Ozawa S (1980) Inthibitory action of adenosine on synaptic transmission in the hippocampus of the guinea pig in vitro. Eur $\mathbf{J}$ Pharmacol 68:483-492.

Palisses R, Persegol L, Viala D (1989) Evidence for respiratory interneurones in the C3-C5 cervical spinal cord in the decorticate rabbit. Exp Brain Res 78:624-632.

Phillis JW, Wu PH (1981) The role of adenosine and its nucleotides in central synaptic transmission. Prog Neurobiol 16:187-239.

Press WH, Flannery BP, Teukolsky SA, Vetterling WT (1989) Numer- ical recipes the art of scientific computing. Cambridge: Cambridge UP.

Prince DA, Stevens CF (1992) Adenosine decreases neurotransmitter release at central synapses. Proc Natl Acad Sci USA 89:8586-8590.

Proctor WR, Dunwiddie TV (1987) Pre- and postsynaptic actions of adenosine in the in vitro rat hippocampus. Brain Res 426:187-190.

Redman S (1990) Quantal analysis of synaptic potentials in neurons of the central nervous system. Physiol Rev 70:165-198.

Scanziani M, Capogna M. Gahwiler BH. Thompson SM (1992) Presynaptic inhibition of miniature excitatory synaptic currents by baclofen and adenosine in the hippocampus. Neuron 9:919-927.

Scholz KP, Miller RJ (1991) Analysis of adenosine actions on $\mathrm{Ca}^{2+}$ currents and synaptic transmission in cultured rat hippocampal pyramidal neurones. J Physiol (Lond) 435:373-393.

Scholz KP, Miller RJ (1992) Inhibition of quantal transmitter release in the absence of calcium influx by a $G$ protein-linked adenosine receptor at hippocampal synapses. Neuron 8:1139-1150.

Smellie FW, Davis CW, Daly JW, Wells JN (1979) Alkylxanthines: inhibition of adenosine-elicited accumulation of cyclic AMP in brain slices and of brain phosphodiesterase activity. Life Sci 24:2475-2482.

Smith JC, Feldman JL (1987) In vitro brainstem-spinal cord preparations for study of motor systems for mammalian respiration and locomotion. J Neurosci Methods 21:321-333.

Stiles GL (199'2) Adenosine receptors. J Bio Chem 267:6451-6454.

Thompson SM, Haas HL, Gahwiler BH (1992) Comparison of the actions of adenosine at pre- and postsynaptic receptors in the rat hippocampus in vitro. J Physiol (Lond) 451:347-363.

Trussell LO, Jackson MB (1985) Adenosine-activated potassium conductance in cultured striatal neurons. Proc Natl Acad Sci USA 82: $4857-4861$

van Calker D, Muller M, Hamprecht B (1979) Adenosine regulates via two different types of receptors, the accumulation of cyclic AMP in cultured brain cells. J Neurochem 33:999-1005.

Van der Kloot W (1991) The regulation of quantal size. Prog Neurobiol $36: 93-130$.

Zhan WZ, Ellenberger HH, Feldman JL (1989) Monoaminergic and GABAergic terminations in phrenic nucleus of rat identified by immunohistochemical labeling. Neuroscience 31:105-113.

Zhu Y, Ikeda SR (1993) Adenosine modulates voltage-gated $\mathrm{Ca}^{2+}$ channels in adult rat sympathetic neurons. J Neurophysiol 70:610620 . 